\title{
A NEW IDEALISM
}

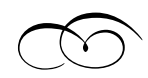

\section{Dewey beyond Morris and Hegel}

$\mathrm{M}$

$y$ main claim in this book is that Dewey's early thought amounts to an original and significant philosophy. This claim challenges the standard interpretation, which holds that aside from helping illuminate Dewey's later writings, his early work has nothing important to teach us; that taken on its own terms it is unworthy of our sustained attention. It may be objected to my thesis that Dewey's early thought is typical Hegelian idealism, reflecting the philosophy of his teacher, George Sylvester Morris, if not simply of Hegel himself, and merely reiterates pre-existing idealist claims. In this final chapter, I will demonstrate that the philosophy I have analyzed throughout this book really is a new mode of thought, specifically a new form of idealism, with sufficient merits in its own right to warrant careful study.

I begin with a summary and reminder of the fundamental logic of Dewey's early thought - the logic of rupture and movement. I then show how this underlying logic differentiates his early ideas from the 
philosophies of both Morris and Hegel, two of Dewey's most important influences. To underscore the continuing relevance of Dewey's early ideas, I then compare them with those of some important contemporary thinkers in Continental philosophy, most notably Theodor Adorno and Jean-Luc Nancy. Dewey's early ideas, we shall find, are still fresh and vital today, and even able to address some of our own pressing philosophical concerns. Lastly, I show that Dewey's early philosophy is important in another way: it actually poses a significant challenge to Dewey's later philosophy in important respects. This surprising discovery serves to show just how potent Dewey's early ideas really are, and it should give pause to those who unquestioningly accept the view that Dewey's later ideas are superior and alone worthy of study. In sum, I hope to show that Dewey's early philosophy is far more sophisticated than generally supposed and makes genuine contributions to philosophical inquiry, including, above all, its ability to confront philosophical pessimism.

The logic of rupture: this is how I describe the early Dewey's general mode of thinking. As we have seen, for Dewey there is no first, un-idealized fact, but rather a series of idealized and meaningful facts. The facts always rupture-break apart from themselves-and move toward something else, something potentially more ideal; for as idealizing selves, we force the facts apart in this way, seeking to render them more conducive to ourselves, more meaningful than they are in their brute givenness. This process of rupture is going on all the time, even unconsciously in our acts of knowledge, and it explains how facts become meaningful; that is, how they are put into relationships with other facts, in terms of which they become significant. Our past experiences and our creative efforts are brought to bear on each given experience; they establish novel relationships for the experience and so generate new meanings for each experience as it comes. The process of the rupture of facts and their subsequent idealization always takes place as movement, as an ongoing, continuing event that occurs precisely through the disruption of what is given before us.

Let us take an example that Dewey himself gives to further clarify the basic logic of his position. Consider, for example, "the law of 
justice" and what it might mean in human life (EW 3: 350). Dewey says two things about this law. First, any collection of individuals requires the ideal of justice to become a society; but, second, the ideal of justice is never reducible to the actual collection of individuals and their behavior. Dewey explains the first point:

The law of justice states a certain relation of active wills to one another. ... To imagine the abolition of these laws is to imagine the abolition of society.... A society in which the social bond we call justice does not obtain to some degree in the relations of man to man, is not society. (EW 3: 350)

The ideal of justice is a necessary condition of any real society.

And yet, this does not mean that justice is the same thing as how justice appears in a given society (EW 3: 350). Justice may obtain in some actual facts, but its meaning does not consist in the actual facts. On the contrary, the meaning of justice lies in the future, in the continued idealization of what justice means in the ongoing movement of the actual society. What justice means at any given point is incomplete-its complete meaning, therefore, lies forever outside the situation, as an ideal toward which the actual situation, in its incompletion, is reaching, but which it never attains. Dewey puts the point in this way:

The very imperfection, the very badness in the present condition of things, is a part of the environment with reference to which we must act; it is, thus, an element in the law of future action that it shall not exactly repeat the existing condition. In other words, the "is" gives the law of the "ought," but it is a part of this law that the "ought" shall not be as the "is." (EW 3: 351)

This is precisely the concept of rupture: "the badness in the present condition" helps give us the ideal for future action: that it shall be different from the present condition. It shall be more ideal. Every society presupposes an ideal of justice, but its actual behaviors may not be just; and yet in their injustice, these behaviors point the way toward what would be just. This is just another way of saying that true meaning, for Dewey, lies not in bare facts (here, the facts of the 
given society), but in facts that have become idealized and that endlessly reach forward toward some future better state (the ideal of justice that emerges out of an unjust condition). The logic of rupture, then, maintains that there is an ideal source of meaning beyond imperfect existing conditions whose absence from these conditions drives us on to find it. With this crucial idea in place, let us turn next to a consideration of Dewey's relationship to other idealists, most notably to his teacher, George Sylvester Morris, and then to Hegel himself.

Dewey clearly had a close relationship with Morris. In a moving eulogy that he wrote, published as "The Late Professor Morris," the reader can detect Dewey's real affection for the older man and genuine appreciation of his way of thinking (EW 3: 3-13). Robert Westbrook notes that "Dewey took all of Morris's courses and quickly became the idealist's favorite student."' Indeed, Westbrook states that his connection with Morris more or less determined the nature of Dewey's early philosophy. In Westbrook's words, "Dewey and Morris worked together," but "Dewey's work in the mid-188os was continuous with that he had done in graduate school, and he was clearly the junior partner in this relationship. His essays and books elaborated on and applied the organic idealism he had learned from Morris and the British neo-Hegelians."' As Westbrook sees it, Dewey's work was derivative of the work of other idealists, especially Morris.

Westbrook's assessment, however, does not get us deep enough into Morris's and Dewey's respective views to really note substantial similarities or differences between them. Westbrook identifies common views and sentiments - the need to overcome alienation, the search for unity between subject and object, the rejection of pantheism in favor of Hegelian absolutism, and so on-but these are general aspects of their thought; he does not provide a detailed appraisal. $^{3}$

Certainly Dewey learned a lot from Morris. To help us understand what he learned, and also to help us understand the specific differences between the two men, I will first examine Dewey's view of his former teacher, and then I will examine Morris's philosophy itself. 
The eulogy Dewey wrote for Morris deserves a closer reading than Westbrook and other commentators have provided. "The Late Professor Morris" was published in 1889, two years after the Psychology, by which time Dewey had fully worked out his own early position. In this important article the young philosopher makes clear what he thinks is of lasting merit in the work of Morris. But even here, in the delicate context of a eulogy, he also makes clear, although perhaps unintentionally, the differences between their viewpoints.

"The Late Professor Morris" suggests that Dewey took three important ideas from his professor. First, he took a version of Morris's concept of idealization. Dewey describes a strange experience that Morris told him about, something like a philosophical breakdown in which Morris's entire understanding of the world seemed, as Morris had said, " "to melt away, and there remained, as the whole sum and substance of the universe, only the empty and inexplicable necessity of being'" (EW 3: 5). A Heideggerian might perceive in this strange experience a fine example of "uncanniness,"4 or a direct encounter with the question of Being that can sometimes vaguely steal over one, "like the muffled tolling of a bell." ${ }^{5}$ Morris himself, however, interpreted it as justifying idealism. For Morris noted that the experience seemed to consist only of "'a chaos of shapeless elements," " after which there immediately returned again " "the world such as it had actually shaped itself in my imagination - the earth, with its green fields and forestcovered mountains,' " and so on (EW 3: 5). This is, to be sure, an idealist interpretation of the event: Morris could see meaning only in the world his imagination had created, not in the brute, given reality of being. Moreover, according to Dewey, Morris emphasized that his imagination had created this world. Morris's interpretation of his strange experience almost perfectly mirrors Dewey's idea of idealization as the basis of the very meaning of the world, and it is highly instructive that Dewey singles out this experience and Morris's interpretation of it to help delineate the late professor's thought. We can safely assume, I think, that in this case the student adopted the insights of the teacher. The parallels between their accounts of idealization are too close to ignore; and it is likely that Dewey adopted some of the 
meanings of his teacher's highly interpreted account of his strange experience and the significance it could have for any concept of idealization. As a matter of fact, Morris insisted that the process of idealization was the result of "'a bent common to the universal mind of man," " which " "more or less blindly" " seeks " to introduce order and permanence" " (EW 3: 5). Like Morris, Dewey, too, came to believe that what we are is something larger than our narrow individual selves.

Second, Morris evidently saw in this direct encounter with " the empty and inexplicable necessity of being' " a potential cause for pessimism, if one were not entitled to idealize being and claim for it something more than brute existence. For in Dewey's rendering of the event, Morris states that his attempt to interrogate existence and find out its meaning all by itself had the immediate result of being negative (EW 3: 5). Additionally, Dewey stresses when describing Morris's character and concerns that his former teacher went on to reject materialism - the granting of superior status to brute matterexactly for its "failure to support and inspire life" (EW 3: 6). As Dewey describes Morris, he battled the pessimistic and paralyzing affects of materialism and won. "He was preeminently a man," Dewey says, "in whom those internal divisions, which eat into the heart of so much of contemporary spiritual life, and which rob ... the will of its belief in the value of life, had been overcome" (EW 3: 9). I think it fair to conclude that here, too, the early Dewey adopted or at least shared his more experienced teacher's revealing concern for the extent to which, in the face of materialism, we are entitled to find value in life. It is almost point for point Dewey's own fundamental concern in his early work.

Third, Dewey took from Morris the idea that social meaning is a symbol of cosmic meaning, though the two philosophers differ in their ways of expressing the idea. Notice this important character trait, and its philosophical significance, that Dewey attributes to Morris:

He found the substance of his being in his vital connections with others; in the home, in his friendships, in the political organization of society, in his church relations. It was his thorough 
realization in himself of the meaning of these relationships that gave substance and body to his theory of the organic unity of man with nature and with God. (EW 3: 10)

This idea about actual social life, when it is successful, serving as the basis for a belief in cosmic meaning is obviously very close to Dewey's own rethinking of the relationship between self and society. It certainly makes one wonder about the extent to which Dewey's idealism is distinct from the idealism of Morris.

But these similarities notwithstanding, fundamental differences between the two thinkers do exist, according to Dewey's account. The most crucial difference is the absence of anything like the concept of rupture in Morris's idealism; and as I have argued, this is the early Dewey's most central concept and indeed his singular innovation. When Morris thinks of the process of idealization, he thinks of the mind's urge " to introduce order and permanence" (EW 3: 5). But in Dewey's account of the process of idealization, the mind seeks not permanence but the progressive development of meanings through continual rupture. True, the self has faith that its own meanings are part of something larger, but this larger something (whether we think of it as the moral community or as a meaningful universe) is the object of faith, and the function of this faith is to keep us generating actual, finite, particular meanings in the world. This is the fundamental point that we have seen at work again and again in Dewey's early philosophy. The early Dewey wants us to understand that "our life is one of progressive realization, not of completed development, of growth rather than of attained being" (EW 2: 260). The craving for permanence that Morris desires is worlds apart from the spirit and letter of Dewey's thought. Dewey embraces process, while Morris wants permanence.

Even more importantly, with regard to the relationship between the individual and the larger, meaningful reality outside of himself, Dewey explains that Morris saw the individual as bearing a " direct relation with the Absolute Mind' " (EW 3: 9). Indeed, in Dewey's view, "the firmness with which he held this truth is the key to all of 
his thinking" (EW 3: 9). Yet Dewey in his own work insists time and again that we bear no direct relationship to this larger reality; for him, the self is always thrown outside of itself, and becomes something more, and so on endlessly and forever, as it develops its infinite capacities and realizes itself in the world more and more completely. This means precisely that there is no direct relationship between the self and God or the Absolute; there is no end to the process toward which the self inevitably and demonstrably tends; there is only the whirlygig of constant movement, along with the faith that this movement leads somewhere. The precise point and function of this faith is to keep the whole process in motion - to keep us embracing life and the process of continual meaning-making. Any claim that this process results in a direct relationship to God is explicitly abandoned by Dewey.

I think this marks a substantial difference. There are idealisms and idealisms. Many share common features, such as the view that reality is shaped by mind, and yet we rightly distinguish between them. The same thing must be said for the idealisms of Dewey and Morris, and most particularly on this score. For Morris, again, as Dewey quotes him, " "the very sense of philosophical idealism . . . is to put . . man in direct relation with the Absolute Mind" " (EW 3: 9). Morris needed to have a direct connection with God. For Dewey, on the contrary, as quoted before, "the self has always presented to its actual condition the vague ideal of a completely universal self by which it measures itself and feels its own limitations.... [W] hat this ... self as complete is, it does not know. It only feels that there is such a goal" (EW 2: 358). We do not bear a direct connection to the universal self, but only feel a vague, unfulfilled longing, the point and purpose of which is to function as "a constant motive power . . . bringing forth the concrete attainments in knowledge, beauty, and rightness" (EW 3: 359). Dewey did not need to know for certain that he was one with God or any higher reality whatsoever; he sought only to provide us with an explanation for the unending process of meaning-making that goes on in the world. His explanation was that as finite beings, our work is always unfinished; there is always more meaning and 
value for us to create in the world. There is always something more, and better, for us to strive to be. This is a fundamental difference of philosophies; it is the difference between a philosophy of vigor and nerve and a philosophy of acquiescence, between a philosophy of action, so characteristic of Dewey's late work also, and a philosophy of submission to its author's deepest metaphysical longings.

There is one more crucial difference between Dewey and Morris. As we have seen, Morris may well have been the source for Dewey's idea that social life is the symbol for cosmic life, so important to Dewey's overall early thought. And yet Morris comes down decidedly more on the religious side of this equation than on the social, whereas Dewey comes down decidedly more on the social side. ${ }^{6}$ Dewey emphasizes Morris's “strong religious nature," while in Dewey's own work one gets the sense that religion is secondary to society (EW 3: 7). After all, in his Outlines of a Critical Theory of Ethics, the outgrowth and fuller working-out of the main ideas of the Psychology, religion is peculiarly absent, while the concept of the moral community comes to dominate the discussion. In applying his insights from the Psychology, Dewey chose to write about ethics and social philosophy, not religion. And even in the Psychology, we have seen that the crux of Dewey's position, its real motive, as it were, is to overcome pessimism by helping us rethink our social relations in such a way that life would be worth living within them. The real motive of Morris's position seems rather to achieve direct contact with the religious element itself, which alone can truly inspire us to live, while social life serves merely as a point of access to this religious element. As Dewey observes, "it was characteristic of Professor Morris that the two writings from which he most often quoted were the Dialogues of Plato and the Gospel of St. John. In the fundamental principle of Christianity, he found manifested the truth which he was convinced of as the fundamental truth in philosophy" (EW 3: 8).

Dewey's definition of the two positions, then, lets us say that his idealism is distinct from Morris's idealism in significant ways. Morris's unwillingness to embrace process, his inability to accept anything less than a direct connection to the Absolute, his subordination of the 
social ideal to religious life-these are fundamental points of difference between the two thinkers. And even if we were to suppose that Dewey was simply a disciple of Morris, the fact remains that Dewey worked out his own philosophy in great, sophisticated detail. And when it comes to philosophy, the devil, we know, is in the details. The sheer comprehensiveness of Dewey's efforts, all that his philosophy purports to explain, alone renders it an interesting philosophical expression. But in any case it seems clear that Morris and Dewey do differ significantly enough - they differ as to the very nature of how one should combat pessimism, which is to say, in fundamentals.

It is important, however, not to rely solely on Dewey's account of Morris to make these points, but also to turn to Morris's work itself to weigh the similarities and differences between the two thinkers. It is one thing to consider what Dewey perceived his intellectual debt to his teacher to be and another to consider what the texts themselves reveal.

Morris's most important and characteristic work is Philosophy and Christianity (1883). ${ }^{7}$ This book originated as an installment of the Elias P. Ely Lectures on the Evidences of Christianity. ${ }^{8}$ Morris's aim in the book is "to show that intelligence, as such, is the true bulwark, and not the enemy, of religion." Philosophy and Christianity tries to show how reason, which can take religion as well as anything else as its object of investigation, does not vitiate religion, but rather confirms and endorses it, especially the religion of Christianity. Morris's basic strategy is to present the latest insights of German idealism in terms of the nature of knowledge and reality and then show how they match, point for point, the religious doctrines of Christian thought. His book is a work of Christian apologetics, utilizing Hegelian idealism as its main philosophical resource. ${ }^{10}$

When we come to the specific ideas advanced in the text, two points become clear. First, Morris holds, as does Dewey, that there is no real separation between subject and object, so that the objective world we find ourselves in already embodies human, subjective meanings. "We have just as much right to say," according to Morris, 
that the subject finds its forms in the object as that the subject puts its forms on the object. The one is just as true as the other. The individual, therefore, as a knowing agent, finds himself set in the midst of an intelligible world, of which he is a part, or to which he is akin, and not placed as a knowing machine, over against a world, which is wholly unrelated to him and refuses to have anything to do with the forms of his intelligence. ${ }^{11}$

This is Dewey's point as well. We find in the world the meaning that we have already put there, so that we can, in effect, feel at home in the world. So far the philosophies of Dewey and Morris are very similar.

Second, Morris holds that we are able to find this human meaning in the world "only in the light of self-consciousness." 12 This again sounds like Dewey, in that they both insist on a higher ideal that would unify subject and object, ensuring that the meaning of one is the meaning of the other. Morris sounds even more like Dewey when he stresses that man's attainment of this higher unity "is still always incomplete. Man finds himself, after all, only as an organic part of an intelligible world, in knowing which he assumes, with reference to it, the attitude of its organic head. This rôle, however, he only assumes; he does not fill it. ... [H] e never completely fills it." ${ }^{13}$ For both Morris and Dewey, the attainment of our highest ideal, the realization of the Absolute, is forever elusive. It is a goal that we never realize.

It is precisely here, however, that the crucial difference emerges between the two thinkers. When Morris explains what he means by our inability to reach the Absolute, he reveals that he means something fundamentally different from what Dewey means. Morris is driving at the idea that we can never be the Absolute; he never for a moment holds, as Dewey does, that we can never become immediately certain of its presence and that this very uncertainty drives us to search for it. Morris says only that we are not ourselves the Absolute, and that our self-conscious activity of apprehending a meaningful world is not the work of ourselves alone: "self-consciousness in man is intrinsically dependent upon an absolute self-consciousness." 14 About our own self-consciousness, we can say: "it is dependent." 15 
But the absolute self-consciousness is totally independent and selfsufficing. "It is the radiating or expansive center of a process which extends over the whole world of intelligence without ever losing itself." 16 For Morris, "the essential truth" of the Absolute "is guaranteed" to us through our very dependence on it. ${ }^{17}$ This is his main point. Having argued that our intelligence helps shape the meaning of the world, he then says:

But now, the world is not created by our intelligence. ... It exists independently of our individual intelligence and independently of the intelligence of the whole aggregate of finite and knowing individuals in the universe. It only remains, therefore, to suppose that the individual subject's synthetic activity in intelligence is not simply or primarily creative, but the rather recreative, not productive, but reproductive. ${ }^{18}$

In other words, Morris holds that our finite forms of intelligence, which give form to the world, are really only forms possessed by the Absolute. Like T. H. Green, while admitting that we create the relations in nature, he nonetheless maintains that our own self-creations really only occur in the bosom of the Absolute and its self-creations. ${ }^{19}$ But Dewey, as we have seen, centers meaning in the finite self pursuing the Absolute, not in the eternal and completed Absolute itself.

Moreover, Morris insists on our immediate connection to the Absolute in this respect, whereas, as we have seen, Dewey insists that there is no immediate connection. In a person's relation to the Absolute, Morris says,

nought can separate him, whether principalities or powers, or things present or things to come. For to this, the everlasting and absolute and ever-present source of his being, he is immediately related. With this he is connected by the innermost springs of his being. It is in this that he immediately lives and moves and has his being. With all else his connection is indirect. ${ }^{20}$

We are ensconced in the Absolute, totally immersed in it, and so always connected to it at an essential level of our being. Such a connection is our most fundamental reality, everything else being secondary 
and "indirect." Indeed, to understand this immediate connection to the Absolute is, for Morris, to become "the true man. It is the creative-redemptive realization of the perfect man, in living union with the Absolute, with God." 21 In Dewey's philosophy, however, our connection to the Absolute always still eludes us. Our intuition of the Absolute, it will be recalled, is never direct or immediate.

Furthermore, the Absolute as Morris conceives of it is a perfect, timeless unity. While Morris does make a point of saying, like any good Hegelian, that "the unity in question is a living unity ... an identity, the very condition of whose existence is diversity," he nonetheless also stresses, again like Green, that this unity unfolds itself in time while the Absolute itself remains outside of time in a pure, eternal state of being. ${ }^{22}$ As Morris puts it, our "knowledge of God, is said to be eternal life,- - not simply the condition of such life, but identical with it." ${ }^{23}$ In intelligence, when we grasp the Absolute, we share in truth, in the eternal life of the Absolute. ${ }^{24}$ And to share in this eternal life of the Absolute means to be outside of time and change. In the life of the Absolute, "the eternal is an everlasting Now; in it there is no distinction of past, present, and future; in this sense it is superior to time. Time is the emblem and the condition of mutability, of change, of impermanence. ... [W] hatever is characteristically subject to the condition of time, is . . unreal, insubstantial . . . without true and abiding reality." 25 Not so with the Absolute, which stands above all change and decay and gives true reality to all things, including those who grasp the Absolute in their own minds. For a human being, "it is only through his participation in an eternal life, that he has in him true substance or reality." 26 Only insofar as a human being participates in the timeless, changeless state of the Absolute does he possess full and actual reality. For Dewey, on the other hand, the finite self is the focus and the idea of the Absolute eludes us. We never have any direct evidence that the Absolute exists as a perfectly realized unity somewhere.

The differences between Morris's philosophy and Dewey's should now be clear. As we have seen, Dewey holds that the Absolute is absent; that we bear no direct connection to it; and that it nowhere forms a perfect unity, but rather that division and disruption are its most 
primary elements, although of course the Absolute does allow us to achieve temporary unities of meaning and experience as determined by the harmonious experiences it seems to make possible. For Dewey, the Absolute is an absent ideal, and herein lies its power. This is point for point different from the ultimate conclusions that Morris draws. Morris, as we have seen, holds that we are fully connected to the Absolute; that we bear a direct connection to it; and that it forms a perfect unity. In a word, Morris, like all traditional Hegelians, gives primacy to eternal harmony in his conception of the Absolute, while Dewey gives primacy to the finite activities of process, development, dislocation, and rupture. Even where Morris makes a point of saying that we will never fulfill the conditions of the Absolute, what he means is that we will never be the Absolute, that we are dependent upon it; but this point in no way takes away from his insistence that the Absolute is immediately present to us as a timeless, changeless, and perfect unity, standing like "the rock of ages, which can never be moved" above the divisions and ruptures of our merely apparent life. ${ }^{27}$ It never occurs to Morris, as it does to Dewey, that the Absolute might itself be a force of rupture and dislocation, and that these negative processes its absence makes possible might be the crucial phases of meaning-making for us.

I think it fair to conclude, therefore, that while Dewey without question learned a great deal from Morris and shared many of his key concerns, he also went beyond Morris in the fundamental features of the idealism he developed. Dewey took what he could from Morris and created something new. He shared Morris's worry about pessimism, and he may have taken from Morris his belief in the necessity of seeing meaning in ideals, including social ideals. But he added to this mix the logic of rupture, the embrace of process, and the uncertainty of outcome, and he worked out in original detail a bold new vision of culture in which realizing oneself, as an individual, makes possible a reciprocal interplay between selves in which the coordinated community can grow in meaning and significance.

Granted, then, that Dewey's early idealism does distinguish itself from Morris's idealism — what about its relationship to the idealism of Hegel? Surely here, if anywhere, we can say that Dewey's idealism is 
not unique; that Dewey-to echo Westbrook's remark about Dewey's relation to Morris-has only "elaborated on and applied" the ideas of Hegel..$^{28}$

But the question is: which Hegel? Hegel's philosophy is notoriously difficult to pin down and define. Or, rather, there are so many versions of Hegel that one must first specify which Hegel one means before asking whether someone is or is not merely reproducing Hegel. If we mean Hegel the philosopher of total unity, of accomplished ideal results, then Dewey's idealism is not Hegelian, since it posits endless progression instead of unity. If we mean Hegel the philosopher who holds that society is objective mind, then again, the early Dewey is not Hegelian, since he thinks of society as consisting of definite individuals who each pursue their own tasks of self-invention, even as they shape the society for the better; Dewey does not think of society as the literal instantiation of the mind of God. If we mean Hegel the philosopher of the dialectic, for whom a real logic runs through things and holds them together, then once again Dewey is not Hegelian, since he holds that rupture is what runs through things-a rupture made manifest above all through feeling, rupture that never once demonstrably comes to closure. It is only on the assumption of faith that Dewey's logic of rupture may possibly cease and give us rest somewhere, whereas Hegel, in some readings, took himself to have rationally demonstrated the logic of the dialectic and had little room for faith. If we mean by Hegel someone who believes in an Absolute Mind that knows all things, as many idealists believe has to exist, then Dewey is not Hegelian, since he believes in finite individuals yearning to realize themselves; and he believes that this yearning for the not-yet-accomplished is the very path to the progressive development of finite meanings.

We can say that Dewey shared with Hegel a deep desire to overcome the problem of alienation, and that he adopted the basic contours of Hegel's solution for overcoming it, as we saw in chapter 1. Like Hegel, Dewey understood modernism to be a negative force that painfully separated the isolated self wholly from the world. And like Hegel, he saw that the way to overcome this separation was to understand that what is outside of oneself (nature, other people) is actually 
part of oneself, when we enlarge the meaning of the self to include the whole fabric of society and of the cosmos. As for Hegel, this is a mystical insight backed up with rational arguments. When he was young, Dewey once felt a healing oneness with things, and sought to rationally justify and explain this feeling through his philosophy. But unlike Hegel—or at least unlike Hegel as traditionally understood-Dewey thought, first, that we can never completely justify this feeling rationally (we can get right up to the point where we nearly can, and after that we need faith), and second, he never deceived himself into thinking that our alienation would ever be perfectly overcome. For him, the effort to overcome it, and to establish human meaning in the world, was an endless process - a process that itself gave meaning to the world. Perhaps this explains why Dewey could become a pragmatist in the end; at the beginning of his career he was already an idealist who was against "the quest for certainty" (LW 4:7). This does not mean that Dewey's idealism and pragmatism are identical, nor does it mean that Dewey's pragmatism is simply a later development of his idealism. As we will see in the last section of this chapter, there are grounds for seeing two distinct philosophies here. The early Dewey developed a form of idealism that affirmed endless process; but this is not necessarily the same thing as developing a form of proto-pragmatism.

But if Dewey developed a form of idealism that affirms endless process, this throws into a new light the relationship that Dewey bore to Hegel. If we wish to understand Dewey's Hegelianism, we need to start by rethinking the traditional conception of Hegelianism, whereby Hegel seeks to bring process to an end and to hold all things together in Absolute Mind. We need to look toward more contemporary and innovative readings of Hegel for a fair sense of the kind of Hegelianism that Dewey in his youth had developed.

\section{Contemporary Comparisons}

Jim Good has done more than anyone to help us understand the relationship between Dewey and what Good calls "the non-metaphysical Hegel," ${ }_{29}$ which I interpret to mean a historical Hegel, a Hegel of 
human situatedness rather than transcendence. But I think we can press the case further and discover other connections between Dewey and Hegelian strains of thought if we turn, not to "humanistic/historicist" readings of Hegel, which ultimately privilege unity, but to readings that emphasize the acts of rupture and separation in Hegel's philosophy. ${ }^{30}$

Such recent Continental philosophers as Theodor Adorno, JeanLuc Nancy, and Slavoj Žižek have shown us a new and fascinating Hegel, no longer a Hegel of the fixed and finished Absolute, where everything works towards harmony, but a Hegel of disturbance, of continual negation and differentiation. Adorno maintains that Hegel's philosophy "is incompatible with any kind of tendency to harmony. . . . His critical thought . . . is not a matter of unbroken transition but a matter of sudden change, and the process takes place not through the moments approaching one another but through rupture." ${ }^{11}$ Jean-Luc Nancy makes a similar argument, to the effect that "Hegelian thought does not begin with the assurance of a principle. It is simply identical to the restless." 32 "This world of movement," Nancy says, "of transformation, of displacement, and of restlessness" is what Hegelian philosophy is all about. ${ }^{33}$ No fixed trajectory constitutes Hegel's Absolute, only ongoing rupture and change. Žižek gives voice to a similar idea when he emphasizes the "negative, disruptive, decomposing aspect" of Hegel's philosophy. He adds that the idea has an important political implication, namely, that the rupture of thought—its negation of things, its "absent centre"-is required for an emancipatory politics that can move beyond existing conditions. ${ }^{34}$

Could John Dewey in his early work have also achieved such an understanding of things? Could he really have arrived, through his studies of Hegel, at ideas similar to those of these late-twentieth-century thinkers? Let us consider once more what we have discovered about Dewey's early philosophy. And as our measure for what constitutes rupture, let us take Adorno's description of it quoted above: it "is not a matter of unbroken transition but a matter of sudden change, and the process takes place not through the moments approaching one another but through rupture." ${ }^{35}$ 
The early Dewey's advocacy of a philosophy of endless process can be seen from this remark, quoted previously: "Our life," he insists, "is one of ... growth rather than of attained being" (EW 2: 260). So there is never a final result. We are constantly making meaning in the world and growing in our own meaning as selves, without arriving at any fixed point. But how does this growth occur? Does it occur as "a matter of unbroken transition" or as "a matter of sudden change"? 36 Do the growing elements of meaning occur because one element approaches another and communicates its meaning to it directly, or does one meaning wholly erupt out of another, a present meaning leaping out of a past one as a new and unforeseen result?

Let us recall what we have seen so far. As we worked through Dewey's conceptions of knowledge, feeling, and will in the Psychology, we learned that for Dewey meaning was constituted in each case by an abrupt shift away from a given element (or fact). The first and perhaps most important instance of this is in the case of knowledge, indeed at the very beginning of all knowledge, with the first occurrence of any mental content at all. We encounter an abrupt shift when we attempt to understand "the relation between the external world, including the organized body, and the mind or self," or, what is the same thing, "the connection between sensations or psychical states and the physical and neural changes which excite them" (EW 2: 37). Dewey is emphatic on this point: "there is no identity between the sensation as a state of consciousness and the mechanical motion which precedes it" (EW 2: 40). He goes even further: "a chasm" exists between them (EW 2: 39). An external motion may precede every sensation, but "sensations are not motions. The sensation of red may have a dependence upon a certain number of etheric vibrations, but as a sensation it is a unique psychical state, having no motion, no vibrations, no spatial length nor form.... [O]ne exists as an objective spatial fact of movement, the other as the unique psychical fact of consciousness" (EW 2: 39; 40). Because of this fundamental difference between them, one cannot be the cause of the other; for one thing can cause another only if the two things are of an identical nature, but in this case they are of different natures (EW 2: 39). 
Moreover, the physical explanation of how mental contents emerge requires that the mental contents are of a quantitative nature, so that, for example, according to the law of the conservation of energy, one quantitative, measurable event passes its energy into another definite quantitative something, and the same amount of energy at work in the physical cause is transferred to the resulting sensation. But in this case "no quantitative transformation can be made out, for the simple reason that the consciousness is not a quantity" (EW 2: 40). Hence, Dewey concludes that there is "a chasm which the law of the correlation of energy cannot bridge" (EW 2: 39).

But a chasm is more like a rupture than continuity. For the early Dewey, there is no continuous relation between an external motion and a mental content; on the contrary, the mental content "is a virtual creation"; it "cannot be in any way got out of" the physical events (EW 2: 42). Mental contents such as sensations are the product of rupture, of a sudden change. "A sensation is not the simple affection of the soul by some bodily change. . . The sensation is the state developed out of and by the soul itself upon occasion of this affection" (EW 2: 42-43). Sensations, in other words, do not develop continuously out of physical events, in definite, explicable steps, but are rather "virtual additions" to reality, something entirely new that is brought into the world by the mind's "power of acting upon itself and of producing from within itself a new, original, and unique activity which we know as sensation"- -through the mind's power, that is, of rupturing given events and moving away from them to create something new (EW 2: 77; 43). Because of this process of rupture, there is no given fact: "knowledge always consists in going out beyond the present sensation. ... [T] he known fact is not a bare fact ... but is idealized fact, existence upon which the constructive intelligence has been at work" (EW 2: 127; 126).

And so it goes for the whole of Dewey's early philosophy. When it comes to memory, for example—or better put, "retention" (Dewey distinguishes between these two, but the distinction need not concern us now) - we can safely say that the past is dead. And yet it lives on as a virtual creation in our minds. "Our past experiences have no 
more actual existence. They are gone with the time in which they occurred. They have, however, ideal existence" (EW 2: 132). How does this process occur? As we have seen, it occurs in much the same way as the tree is affected by external nutrients but takes them up and utilizes them in its own unique ways, according to its own structures.

As the tree is not merely passively affected by the elements of its environment - the substances of the earth, the surrounding moisture and gasses-as it does not receive and keep them unaltered in itself, but reacts upon them and works them over into its living tissue-its wood, its leaves, etc. - and thus grows, so the mind deals with its experiences. (EW 2: 132-33)

Once more, the mind takes up some external element but does not merely reproduce it. Some external event happens. The mind gives the event an ideal meaning "by connecting it with the self, and thus putting into it significance, which as bare existence it does not have"something, again, which is a virtual creation, because the bare existence simply does not possess this meaning in itself (EW 2: 122). Now, in the case of memory or retention, the original event that occasioned the process eventually passes, but the ideal existence of the event that the self created for itself is "wrought into the character of the self," and because of this the self retains its ideal meaning of past events within itself as it continues on in its life (EW 2: 132). It has memories, or retentions, which it can carry into new experiences. But note that here, too, as with sensation, there never occurs within this process an element of continuity. There are, in fact, two acts of rupture involved: first, the original event is given an ideal meaning by the mind, a meaning which the "bare existence" simply does not possess, a meaning which is simply not there, and which must be created by the self out of its own resources; and second, the ideal existence (the thing remembered) continues on in the life of the self even though the original event no longer has any actual existence, that is, even though it has no direct, continuous connection to the self (EW 2: 122). True, the original event did form our habit of being able to act differently now, but this is not the same thing as the mental image, which is a new present creation of a past and no-longer-existent event. 
Consider next the transition that occurs between perception and imagination. With this case, we begin to move into an account of how the logic of rupture is involved in feeling as well as in knowledge. In perception, the mind has taken up sensations and produced in relation to them a new object, which itself is composed of almost no sensations (this is another act of rupture): "in the perception of an object, as an apple, there are actually present, it will be remembered, only a few sensations," since the unity of the object is not something given in the sensation of red, round, sweet, and so forth. "All the rest of the perception is supplied by the mind" (EW 2: 168). More specifically, the object of perception is a product of the imagination:

The mind supplies sensations coming from other senses besides those in use; it extends and supplements them; it adds the emphasis of its attention, and the comment of its emotions; it interprets them. Now all this supplied material may fairly be said to be the work of the imagination. The mind idealizes-that is, fills in with its own images - the vacuous and chaotic sensations present. (EW 2: 168-69)

So the imagination adds new content to our sensations, and the result is our perception of an object. How does this "growth in meaning" (EW 2:184) occur? The growth cannot come about from the imagination simply taking up material that is already present in our sensations; for none of these elements is present in the original material (say, the isolated perception of red)—rather the mind must give its own "emphasis of attention," "the comment of the emotions," and so forth. This is all the new and original work of the imagination, which it supplies to the sensations by virtue of its own powers.

But now-and here is the really important point—-the mind makes a transition from the perception of an object, in which the new, added, ideal images "are swallowed up in the product, so that the object of perception appears to be a mere thing, which exists without any ideal connections," to an object that is the product of the imagination proper and is recognized as entirely ideal, such as an imaginary apple (EW 2: 169). How does this growth of meaning occur? 
How can the mind move from the perception of an actual object to its imaginary stand-in, or even to an imaginary object pure and simple, an image without any direct reference to an object? Dewey's answer is that when this occurs, the image is "severed from connection with some facts actually existing" (EW 2: 169). His choice of words here, of course, is interesting-the image is "severed," or cut loose, from any actual thing. The ideal element already at work in the perception of an object "is freed from its reference to some existence, and treated freely; that is, as an image, not as tied down to some thing or event" (EW 2: 169). And this severed image "is not confined to isolation and combination of experiences already had, even when these processes occur under the influence of sensitive and lively emotion. It is virtually creative. It makes its object new by setting it in a new light" supplied by the mind itself (EW 2: 171). Once again, it is difficult to see how this process can occur through the elements of meaning making contact with one another; it seems rather to involve their separation. An image is "severed" from reality; it is "not confined to . . combination of experiences already had"; "it makes its object new" (EW 2: 169; 171). This is the language of rupture.

It is the same with Dewey's account of our feelings. "In aesthetic feeling," for example, "we advance beyond ... and feel the relation which some experiences of ours bear to an ideal. . . . [T] he self . . . is taken beyond its limitation to its immediate sensuously-present experience, and transferred to a realm of enduring and independent relations" (EW 2: 245). These relations do not exist in actual fact; the ideal cannot derive from them (EW 2:42). It is similar to the feeling of sympathy. This feeling is not at work in our relations to others; rather, it must be wrested out of these relations. Sympathy is "an active interest in others," in which we must go out to the experience of the other and allow his experience into our own life (EW 2: 285). The feeling does not exist without this active interest and projection: it is the result of something the mind does, a certain way that it breaks away from our own self-interest and creates something wholly new, a new feeling of absorption in the other and the resulting feeling of connection. 
Consider next Dewey's conception of the will, and the different ways that disruption and separation are involved in willing. Physical control puts the body in check, and prudential control manages our actions in order to help us achieve results (EW 2: 320). But each of these forms of control results in actions that are incomplete, that are only arbitrary and one-sided in the demands they make upon us, while in moral control we find "the absolutely obligatory end. It alone is absolute end" (EW 2: 320). Moral will fulfills all the other acts of willing that would otherwise be merely contingent exertions. So we would expect, in this view of things, that morality would be the last word about willing. But Dewey emphasizes that the moral will never perfectly completes itself: "the moral will is incomplete or partial in its action" (EW 2: 360). "The will as ideal and the will as actual have not been truly unified" (EW 2: 360). To have any hope that they could be unified requires the religious will. It requires faith. But how does this growth of meaning occur? "Religious will declares that the perfect will is the only source of activity and reality"-it declares this, asserts it (EW 2: 360). This assertion comes from an act of will, a pure choice, a free self-determination to believe. Nothing in the moral will compels us to this result, for the moral will is imperfect, always constituting a division. That any unity could come out of it requires a total shift, a new assertion-in short, rupture.

And the religious will itself is not the completion of the process either, as we have seen. Having faith that our ideals are at the basis of fact does not make it so. But faith allows us to go on; it constitutes a "motive power" for us to keep creating meanings (EW 2: 359). Faith, or "the religious life," is the explicit "recognition" that "the final reality for man is that which cannot be made out actually to exist," precisely since it is an ideal, and in faith we affirm the supremacy of the ideal (EW 2: 292). The moral life itself, in any case, requires rupture to move beyond itself. And the moral life is also itself fully constituted by processes of rupture. "Man's moral nature is in process of realization," Dewey explains, "with every new realization of personality comes a higher ideal of what constitutes a true man" (EW 2: 296). This process of increased meaning goes on 
without any past determination, without continuity: "the heart of the moral life lies in the free personal determination of right and wrong. No set of rules can take the place of this personal determination" (EW 2: 297). This is why the "degradation of manhood" is always possible as well as its realization (EW 2: 296). But in any case the moral life is constant disruption, constant upheaval, without continuity with the past - the birth, in every instant, of new possibilities. Insofar as we must speak of a "moral law," we must recognize that it

is thoroughly individualized. It cannot be duplicated; it cannot be for one act just what it is for another. The ethical world is too rich in capacity and circumstance to permit of monotony; it is too swift in its movement to allow of bare repetition. It will not hold still; it moves on, and moral law is the law of action required from individuals by this movement. (EW 3: 352)

I take this passage to mean that the process of rupture is constantly going on in the ethical world-in other words, no event is simply repeated and "duplicated" in our lives, but rather every event counts as a wholly new addition - and that any "moral law" that might be applicable to this process of rupture is itself a product of this process of rupture.

This is similar to what we saw about justice at the beginning of this chapter. In the case of the law of justice, "the 'is' gives the law of the 'ought,' but it is a part of this law that the 'ought' shall not be as the 'is'” (EW 3: 351). Said another way, any ideal of justice can emerge only in reference to some actual, moving, imperfect, and unsettled ethical world, just as any sensation can emerge only on the occasion of an external motion; but the ideal of justice is not identical to the actual ethical world in reference to which it emerges, just as the sensation is not caused by the external motion that is the occasion for the sensation to occur. There is an upheaval in the heart of the ethical world; justice is not given there; the ideal of justice is born. It is the ideal of justice toward which the actual world should tend, but the ideal is not present there within it. 
We can sum up these results in a few words. In Dewey's view, the ideal makes itself present negatively, that is, by leading "to discontent with every accomplished result," which "urges on to new and more complete action" (EW 2: 358). There are "dim and vague feelings which surge for expression in every human being" (EW 2: 278). We do not know what the ideal is; we do not know what it demands of us; we do not know toward what we should be striving. "What this will or self as complete is, it does not know. It only feels that there is such a goal" (EW 2: 358). All this is just to say that everything is always unsettled. Every "this is it here," one might say, turns out not to be "it." The ideal functions as an inexhaustible resource preventing any actual fact from summing up reality. Every fact that presents itself as summing up reality will always be split up; it will always exist in a divided state between what it is and what the ideal version of it is, or what it should be. Rupture will always occur in the very heart of existence.

This does not mean that there is no progress of meaning - that we should despair of ever attaining meaning. All along the way meaning is being attained; with every leaving off of some past, incomplete meaning, we progress toward a new and possibly better meaning, and sometimes partially achieve it, a meaning that we feel approximates, through its harmony, the ideal we yearn for. As we partially realize the ideal, we inch closer to it. Faith is the embrace of this process, the affirmation of life, defined as forever capable of growing in meaning.

The logic of rupture and the meanings it makes possible can be summed up in the following passage:

The will is in itself universal, and this presence of the universal element must prevent the self resting in any realized attainment. It must form the spring to renewed action. ... This real self . . . holds before itself ... an empty ideal without content. . . What it is ... this we do not know. But this empty form is constantly assuming to itself a filling; as realized it gets a content. Through this content we know what the true self is. (EW 2: 319)

The present fact always comes up short of the ideal. The fact is therefore disrupted and must give up its claims to supremacy. A new 
meaning emerges, and to the extent that it approximates the ideal we yearn for, there is meaning. But this approximation, though meaningful, will never be the complete ideal, and so there will be rupture again, and so on and on.

But if this is the case, and the logic of rupture defines the early Dewey's position, then we have reached a surprising result. For the logic of rupture is also the defining element of much cutting-edge Continental philosophy that also draws on Hegel. As we saw with Adorno, Nancy, and Žižek in their uses of Hegel, disruption is the driving force, pointing to an unrealized ideal to which we should aspire-and so it is also with the early John Dewey. Adorno, for example, insists that we should "attempt to contemplate all things ... from the standpoint of redemption," and this sounds a lot like Dewey's insistence that we must always judge our present experience to be inadequate as measured by its absent ideal. ${ }^{37}$ In any case, these thinkers have taught us that Hegelianism ought to imply the logic of rupture, and we have just seen that Dewey employs this logic - and that he may even have developed it on his own from his reading of Hegel. But let us be more specific and see whether any definite links can be made between the philosophy of the early John Dewey and the philosophies of some of these more recent thinkers.

When Adorno offers his interpretation of Hegel as a philosopher of rupture, he does so in order to make the larger point that Hegelianism after Hegel "is all a regression." "His system," Adorno explains, "is not an overarching scientific system any more than it is an agglomeration of witty observations." But nonetheless this is how most people have understood Hegel's work. They have either reduced it to "clear methodology and iron-clad empiricism" or have seen it as an overarching scientific system and "missed the concrete content on which Hegel's thought first proved itself." What Adorno wants people to realize is that empiricism and speculation go together for Hegel; they cannot be separated. More specifically, Hegel insists on totality, on the reality of the whole, but this totality is not something that exists ready-made outside of events; it is rather a result and product of finite, particular events as they unfold. "If Hegel's whole exists 
at all it is only as the quintessence of the partial moments, which always point beyond themselves and are generated from one another; it does not exist as something beyond them. This is what his category of totality is intended to convey. It is incompatible with any kind of tendency to harmony." The idea, in short, is that the rich, unfolding nature of actual experience yields ideals; it blossoms into them, as finite particular moments somehow manage to "point beyond themselves"; and the Absolute whole, then, is nothing else but the jagged, unsteady way in which all of these moments together unfold in the real, messy world of everyday life. Speaking of Hegel, Adorno says, "he knows that the whole realizes itself only in and through the parts, only through discontinuity, alienation, and reflection." This is identical to Dewey's idea that "facts" could themselves be consistent with "thought," with a more human and orderly universe, if we take them as they occur in their various patterns of emergence. ${ }^{38}$

That is to say that for Hegel, the Absolute does not impose forms on reality, but instead, forms emerge from it. Due to its absence, the perfect ideal makes itself felt in each finite particular, and the process is driven on beyond itself toward something better and more. Events in their "immanence" move unsteadily toward the Absolute. Hegelian idealism "permits nothing to remain outside the subject, now expanded to become infinite, but instead sweeps everything along with it into the current of immanence." "Hegel's much-admired material richness is itself a function of his speculative thought," and yet, the speculative moment, of belief in the infinite subject, the Absolute, is derived solely from the particular moments as they unfold in their disharmonious, unsteady way, as in life. "Hegel," as Adorno puts it, "is driven by the idea that knowledge, if there is such a thing, is by its very idea total knowledge, that every one-sided judgment intends, by its very form, the absolute, and does not rest until it has been sublated in it." And again: "Hegel everywhere yields to the object's own nature ... but it is precisely this kind of subordination to the discipline of the thing itself that requires the most intense efforts on the part of the concept." 39 From within events themselves, as we follow their various connections, which are never seamless and steady, but rather discontinuous and 
sudden in their change, we can nonetheless discern an emerging whole, a progression of the ideal, which makes itself more real. Facts, in all of their messiness, nonetheless go beyond facts and become ideal.

Such a position is crucial to much Continental philosophy. The worry is that, in being reduced to facts, to what actually is, we lose any resource for resistance to what is. The strategy here, in Adorno's rendering of Hegel, is to employ the facts themselves as disruptive, as unstable and so capable of "sudden change," 40 so that their necessity is loosened, and they provide within themselves the resource for idealizing the world and working toward progress, toward something better than what the facts themselves, if fixed in their nature, would allow. Continuity would seem to imply necessity, the acceptance of the causal chain and what must come next from the facts, while rupture from within the facts permits, on the other hand, a weakness in necessity itself, a gap in which new, unforeseen events and free decisions can occur. Hegel's Absolute is the ideal of freedom making sure to be present in every otherwise determined series of facts. It is the precondition of distinctly human meaning in the universe and the precondition of the progression of meanings toward something better than the present state of things. But again, the crucial phase of this conception is that the facts themselves erupt into freedom. Freedom is unassailable, precisely because it is not imposed top-down upon events in the world (a world which in that case would offer resistance to it), but rather emerges from the world itself in its own development. ${ }^{41}$

The crucial moment of this Hegelian strain in Continental thought, the moment of the immanent ideal as the point of access to freedom from how things actually are, freedom from the necessity of facts, is expressed well in the work of Jean-Luc Nancy and his appropriation of Hegel. Nancy, too, insists that Hegel is a philosopher of rupture. For Hegel, as Nancy sees it,

this world, the realm of the finite, shelters and reveals in itself the infinite work of negativity, that is, the restlessness of sense. . . It is in this way, in the restlessness of immanence, that the spirit of the world becomes. It neither seeks itself (as if it were for itself an 
exterior end) nor finds itself (as if it were a thing here or there), but it effectuates itself: it is the living restlessness of its own concrete effectivity. ${ }^{42}$

The Absolute is immanent; it is the working through of the facts themselves. And this working through involves a dissolution of facts, of the finite world. It is destroyed and remade. There is a negativity involved, in which things are undone and then put back together in new ways.

To characterize this process as a form of "restlessness," moreover, is to say "that there will therefore be no foundation." We are always in the midst of an unsettled world. There is no first point to return to, as in Descartes; "everything has already begun. . . . [T]he course of the world will not be stopped in order to be recommenced.... [I]f the thread of history is broken, this happens of itself, because its very continuity is only division and distension." To speak of the Absolute's restlessness is also to say that there will be no end state; there is an "absence of completion." For Hegel, according to Nancy, "the infinite or the absolute will be presented in no determinate figure. There will be other figures, but they will now be known for what they are: successive forms in passage, forms of passage itself, and forms born away by passage. The finite figure thus presents, each time, only itself-itself and its infinite restlessness." There is one dynamic process, forever unsettling itself. For what reason? So that meaning can be made; so that freedom from facts, from getting lost in any static substance, and a subsequent movement toward greater meanings, can occur. ${ }^{43}$

Thus, for Nancy in his appropriation of Hegel, the static element in life is removed, and only in this way is freedom possible. Restlessness is required for this result, undoing every given. Meaning, or "sense," 44 is made in this way: "it is an upsurge in the course of the given, a rupture, nothing that could be posited as such. ... Which means: negativity, hollow, gap, the difference of being that relates to itself through this very difference." 45 This is what Hegel means by the Absolute, according to Nancy. It is not an accomplished result, not 
a ground he presupposes, but rather the lack of ground of an everdeveloping free process. "Hegel, if one likes, presupposes the absolute. But this presupposition is made precisely in order to ruin all presupposition or pre-givenness." ${ }^{46}$ What exists is a process that disrupts every given: a "power of the negative that inhabits the gap where relations open, and that hollows out the passage from presence to presence: the infinite negativity of the present." 47 Not the final unity of separate moments, not guaranteed harmony, but inevitable disruption characterizes Nancy's conception of the Hegelian Absolute, the undoing of every given in its due time.

And this negative process, this inevitable upheaval and unsettling work of the Absolute, is one with the ideal of freedom. But it is also the very process by which meaning is made. The reason why this is possible, why negation can give rise to positive meanings, is because of what Nancy identifies in Hegel as the " 'negation of the negation.'” The first negation is negation of the given. Negating the given, I become free from it. "If I penetrate this first truth, that neither the stone nor the ego has the value of simple being-there or of an identity ... this penetration is already liberation." I become free from having to be this or that, or having to submit to this or that. We realize that "being is in itself nothing," but this realization by itself must also be negated, or else we have not attained real freedom, but only perhaps "an abyss or lack," a total negation. Thus,

the second negation denies that the first is valid on its own: it negates pure nothingness, the abyss or lack. It is the positive liberation of becoming, of manifestation, and of desire. It is therefore self-affirmation. But as this liberating affirmation is not a return to the point of departure- to the stone or to me, which in turn was already only a derived given, a provisional deposit along the way and the fleeting instant of a presentation-it is also not a new, simple position.

What Nancy means here is that the given is first negated; and then this negation is negated, so that something definite and positive emerges. But what emerges is not simply a repetition. Having been the result of no given, it has been freed. It is a positive free thing, as, 
for example, are any of the things I have made (or that have made me), through my own free self-creations: "the stone in my slingshot, in the wall that I have built, or in the statue that a sculptor exhibits to us, indefinitely liberates itself from its exteriority, enters into a history and into multiple senses, and brings us along with it. The result is again a liberation - and that is what negativity means." When we negate the given, for example the stone in our midst, we do not, however, remain in the realm of pure negation, but rather, negating our first negation as well, move to the point where the negated given takes on positive content and allows us to create ideal meanings of our own out of the pure negation. We create a positive meaning for the stone. ${ }^{48}$

And here is the crucial point: in reaching positive, ideal constructions through double negation, we do not rely on any foundation to our constructions, nor do we ground them in given facts; and so we attain freedom from the given, while at the same time coming to possess meanings. This liberates us from reduction to mere physical nature, or to any alien necessity, while also making meaning in the world possible for us. It allows us, in the end, to feel at home in the world we inhabit. Nancy expresses this point by saying that "truth comes back to us. It finds or happens upon itself as us, and it is to us that it is entrusted." ${ }^{49}$ "To us: to the upsurge of our existences, together, as the surging up of sense. To the upsurge of this, that the world is precisely what does not remain an inert weight, but what manifests itself as a restlessness. This restlessness is not only ours, it is itself 'us'-that is, it is the singularity of singularities as such." ${ }^{50}$ In a word, there is no foundation to the world, but only the actual events of the world, such as they are, and also the free, developing possibility of their becoming more ideal, more meaningful to us as time goes on. There is only the world; but the world, in its freedom, in its "restlessness," in its tearing away from every given, enables meanings to emerge, which we can, at times, come to possess and to enjoy as "sense," as that which is significant and makes sense.

I submit that Dewey's early philosophy closely resembles such reflections as these, and for this reason it goes beyond traditional versions of Hegelian philosophy, such as were offered, for example, by 
the British idealists. We have already seen how there is no foundation to meaning-making for the early Dewey. Each time the given is negated, but there is no first something that anchors the process. We have seen, too, how for the early Dewey ideal meanings are nonetheless made beyond the given, meanings which then take on positive sense and substance in actual, harmonious states of experience that we (temporarily) attain. We have also seen that the Absolute is not a timeless unity or eternal substance for Dewey, but an ongoing process, a kind of unsettling "restlessness," as Nancy has put it. Lastly, it must be stressed that Dewey, too, saw that freedom and feeling at home were essential to this process. Our knowledge, for Dewey, is never simply a matter of conforming to what is. On the contrary, "we know the world because we idealize it" (EW 2: 211). But in idealizing it, we put the self into it, and when we realize that we are doing this, that "more and more of the activity of the self" is "implied" in our knowledge of things, then we "form the conception of freedom, as we recognize that the process is one which goes on through self alone" (EW 2: 211). We come to understand that the world is a free creation of selves. A free world, moreover, is one in which we can feel at home as human beings. Unlike an alien and determined world, it is one in which "personality . . . shall itself be a moving force counting for something in the universe" (EW 3: 42), and it is for this reason that Dewey wishes to emphasize the free, idealizing aspect of our knowledge of the world and its events.

The early Dewey, immersed in Hegel, was, in effect, a Continental philosopher. He shares the same fundamental impulse: to create a space for resistance to the given, a space for human beings to count in the course of the world, a space that prevents us from being "the playground of natural forces" (EW 3: 42). Moreover, he had an advanced understanding of the Continental tradition, anticipating a way of reading Hegel that has only recently been advanced by such thinkers as Adorno and Nancy. He went beyond his contemporaries in the nineteenth century, beyond his teacher, Morris, and beyond the British idealists, who themselves could envision only a fixed, static, and atemporal Absolute, a more pristine Absolute, which acted 
like a metaphysical foundation securing with necessity the world's development.

The key to Dewey's advance, I believe, is his early antifoundationalism, which has emerged clearly in the course of this study. It is this insight that brings his early philosophy closer to our times. There must have been something in Dewey that freed him from requiring the fixed and firm basis to things that those around him required as the way to overcome pessimism. He could live with a greater amount of fluidity and uncertainty, although he shared with his contemporaries (and recent thinkers too) the need to surpass pessimism and to demonstrate the existence of a meaningful world.

To see this antifoundationalism at work and to further confirm the reading of Dewey presented here, consider one more example-an example pertaining to the social and political realm, a realm to which, as I have noted in previous chapters, some of the early Dewey's most important insights are directed. We will return to the case of justice that introduces this chapter and consider how a recent Continental philosopher, also influenced by Hegel, handles this conception. I choose Jacques Derrida as a fitting, if surprising, example of a contemporary whose thoughts on justice bear comparison with the early Dewey's conception of justice. ${ }^{51}$

To understand Derrida, we must understand his concept of "iterability." As Niall Lucy makes clear, Derrida believes that ideals exist, such as justice, morality, truth, and so on, but he thinks that in order for them to exist they cannot be reducible to any of their present instantiations..$^{52}$ Each instance of an ideal is repeatable, and when it is repeated it is always different from its previous instance. Any realized ideal is therefore both what it is and not what it is. The ideal can be at work in the situation, but there is always something more to what it is than any actual instance of it. When the ideal repeats itself, it will be different, and when it is different of course it will not be the same. "Iterablity refers to this structure of repetition-as-difference, which both enables and limits the idealization of every single thing's singularity, purity, presence." ${ }^{53}$ Because of iterability, deconstruction can take place; that is, there can be no given, purely present, and strictly 
identifiable object or event that we could privilege above all others for its secure, foundational certainty. Every instance of an ideal ruptures and splits into what it is not.

And yet, of course, ideals still do exist and can guide our lives. Lucy is again instructive: he reminds us that "the concept of iterability doesn't commit Derrida or deconstruction to nihilism, relativism, obscurantism," and so on. "Since Derrida admits to ideality ... how could he ever be against values and beliefs, as if to say anything goes? Rather than seeing iterability in opposition to ideality and identity, then, we should see that, as the precondition of ideality and identity, iterability is opposed to the certitude of ideals, the dogma of beliefs, the self-assurance of identities and the constancy of values." ${ }_{54}$ Ideals exist, but any one instance of an ideal is not the ideal, although the ideal must grow out of such instances. What follows is that we have ideals, we function according to them and use them, but we never have the certainty that we own or possess the ideal.

An important example that helps bring out this feature of all ideals, for Derrida, is the ideal of justice. For Derrida, justice is employed in the law courts, and so on, and does not exist outside of them, and yet we would be wrong to mistake the court's decision for justice. In Lucy's words,

a verdict seen as arbitrary or whimsical would never be seen as just; and so there is no question (on Derrida's account) that justice is not outside the law in a transcendental sense. But while justice is never absolutely outside the law, neither could we say there must be justice once 'the law has run its course.' We cannot think that justice remains to come until the court settles on a verdict, at which time there is justice. Out of respect for its radical undeconstructibility we cannot afford to think of justice as something that happens in the present-as something belonging to presence. We could never say that, at this very moment, there is justice. ${ }^{55}$

We approximate justice, but we never reach it. The instances of being-close-to-justice are where anything like justice must occur; anything like justice occurring must grow out of these instances and 
meet their specific needs. But no instance of an approximation to justice adequately defines a just situation, or perfectly meets the ideal, which always still exists to unsettle our present efforts and make us move forward to try to realize ever more instances of justice and come closer to the ideal.

It is the same with Dewey's concept of justice, where, as we saw, "the 'is' gives the law of the 'ought,' but it is a part of this law that the 'ought' shall not be as the 'is'" (EW 3: 351). Actual instances of justice exist in some situations; the ideal is partially realized in what a Hegelian would call a harmonious experience. But the justice we approximate in the situation does not exhaust the ideal of justice, which keeps its distance, as it were, and therefore functions for us as an important resource for creating more and better instances of justice in every future situation. Justice exists, but it is never fully realized. We never have the certainty, therefore, that we have reached justice in the present case, only the need to unsettle that case as it is, and to move forward to approximate the ideal as best we can in the case at hand. Derrida himself, like Dewey, even speaks of such ideals as justice as really being about the future, about meanings that could still be possible (EW 3:351). ${ }^{56}$

One might continue with this comparison between the two thinkers and find other surprising similarities. Derrida's concept of democracy, for instance, resembles to some extent Dewey's vision of culture beyond modernism. All existing political systems, including democratic systems, imply identity, the categorization of the other person-so that we can say who this person is and who that (for example, is he for us or against us?). But a political system in which this occurs would never be democracy, because in it people would not be left to stand as who they are and be enabled to help shape the society as real individuals, beyond our categorization of them. So, we must not confuse our current democracy or, indeed, any democracy whatsoever, with "democracy-to-come," the ideal of democracy that we should keep striving to reach. ${ }^{57}$ "But of course even to imagine the impossibility" of this new democracy "one has to be in some place that is other than purely imaginary in itself. And that place ... is the 
place of democracy today." 58 So, again, as in Dewey's philosophy, here too the instance of a better society must grow out of a present society, but it cannot be wholly identified with the features of that society-it would be that society perfected. Moreover, it would be a society (for Dewey as for Derrida) in which each self is not cut off from its relationship to others (each self is not fixed in its identity and its identity exhausted), but each self would be enabled to become itself, to be an individual, and yet at the same time would be helping to constitute the very fabric of the society as a democracy.

What it comes down to, for both thinkers, is that there exists an ideal community that brings us together, but we must not mistake any actual community for this ideal. A space needs to be set apart, even as the condition of any real community, from which the real community may draw its inspiration and meaning, but the real community can never come to occupy fully this space. The ideal works in and through actual events as they develop, but these actual events never exhaust it. It retains its separateness, its meaning "out there," beyond, as the necessary precondition of the meaning of the actual community, which always lacks the full ideal, but drives towards it precisely because of this lack.

I would not push the comparison too far, but there appear to be surprising similarities between Dewey's early philosophy and the philosophy of Jacques Derrida. And the main basis for these similarities seems to be, if not a shared new reading and development of Hegelian idealism, ${ }^{59}$ then at least the logic of rupture. Deconstruction, as I understand it, reveals the lack of identity between the actual and the ideal, the gap between them, which keeps us striving to render the actual more ideal, even as we realize that the ideal is never the actual. And this is what philosophy means for the early Dewey, for whom the given fact is always idealized, but imperfectly so; and this imperfection "serves as a spur to the actual self to realize itself" and to try to move closer to an ideal version of itself, which it nonetheless does not yet know and cannot yet attain (EW 2: 358).

But there would seem to be this important difference between the early Dewey and these Continental philosophers: Dewey offers a 
more comprehensive and constructive account of the processes of rupture than do these recent thinkers. For he tries to explain almost every feature of human life in terms of these processes-sensation, perception, memory, imagination, judgment, reasoning; feelings in all their different grades and meanings (including feelings of triumph, defeat, brooding, drudgery, play, envy, cheerfulness, melancholy, malice, beauty, ugliness, hatred, and love); physical, prudential, and moral control; the religious will. It is a monumental effort, and none of the more recent thinkers I have mentioned has tried to accomplish anything nearly so vast in scope. Moreover, this effort is constructive, not merely deconstructive, in the sense that it offers positive (if always imperfect) recommendations for intellectual, emotional, moral, religious, and social ideals to strive for; for example, ideals of sympathy or health.

This does not mean that Dewey's early philosophy is better than these other philosophies. Many of the recent thinkers I have mentioned refuse to be system-builders, or refuse to state positive ideals, and for very definite reasons; and they might critique Dewey's early effort for its pretensions along these lines. But what the greater comprehensiveness and constructiveness of Dewey's early philosophy of rupture does reveal is that, again, Dewey is working with the same basic logic, the logic of rupture, as are these thinkers; and that there is more work to be done to explore these lines of comparison more fully, and to determine which type of employment of the logic of rupture, systematic or nonsystematic, possesses greater philosophical merit.

That we can make such comparisons, in any case, indicates that Dewey's early philosophy is far from naïve and unsophisticated. This is a philosophy that invites comparison with some of the most important and interesting philosophical theories today.

\section{Dewey versus Dewey}

That the early Dewey was an antifoundationalist, as are the recent Continental philosophers with whom he favorably compares, may 
tempt us to see direct links between Dewey's early and later thought on this point, since the later Dewey is also very much antifoundationalist in orientation. Perhaps throughout this study the reader has seen in the early Dewey's philosophy crucial, even formative, connections with his later philosophy, whether in the area of his antifoundationalism, or in his view of us as active beings, or with respect to the concept of growth or some other concept. While there are important threads that run through both philosophies, we must not suppose that the sole significance of Dewey's early position lies in its anticipation of his later thinking, or, noting that Dewey's later position retains key idealist elements, view his idealism as significant only for the way it lives on in his pragmatism. For there are fundamental differences between Dewey's earlier and later philosophies that cannot be easily reconciled; and each period of the philosopher's work needs to be taken on its own terms.

The two Deweys differ, for one thing, on the status of the Absolute. For the early Dewey, the Absolute is the crucial resource that enables us to negate every given and move on to create better meanings. The later Dewey seems to reject the concept of the Absolute, or at least ignore it, as when he criticizes Hegelians for putting too much stock in it (see, for example, LW 4: 51-52). A second major difference concerns the theory of truth. The early Dewey offers a coherence theory of truth, while the later Dewey insists upon an instrumentalist or pragmatic theory of truth. A third major difference is that the later Dewey does not seek for the good life, but only the better one. ${ }^{60}$

The most fundamental and unavoidable difference between the two philosophies, however, is this: the early Dewey explains meaningmaking primarily in terms of rupture, while the later Dewey explains it entirely in terms of continuity, at least in his naturalism. ${ }^{61}$ The later Dewey maintains that there is continuous development from the biological to the cultural, a claim that is crucial to his whole position, according to which there is no split between mind and matter, and we are fully natural creatures, even in our spiritual and cultural products. Indeed, the later Dewey explicitly defines "the idea of continuity," which he embraces, as an idea that "excludes complete rupture... 
the appearance upon the scene of a totally new outside force as a cause of changes that occur" (LW 12: 30-31). The idea of continuity, according to the later Dewey, "precludes complete breaks and gaps" (LW 12: 30). But breaks and gaps, as we have seen, are just what the early Dewey insists upon.

To better appreciate this crucial difference between the two Deweys, one might pit them against one another. Let us suppose, for example, that one looks at the idea of continuity from the perspective of the logic of rupture. Instead of assuming the later Dewey's superiority, as many Dewey scholars might, let us speculate whether the early Dewey could mount a critique of the later.

It is conceivable that the early Dewey's emphasis on rupture could explain more than the later Dewey's emphasis on continuity. As Slavoj Žižek has argued, drawing on the works of Freud and Lacan, it takes a violent pulling away from our immediate life and the consequent repression of its desires (and their deepening inward focus) to generate the cultural norms (or what the early Dewey might call the ideals) by which we can live. Our repression of natural desires focuses them inward, where they intensify, and an eruption of new cultural creations occurs as their new outlet and manifestation. Žižek puts the point in an interesting way, which is worth quoting at length. Referring to his own original interpretation of Hegel's concept of the subject, he writes:

The subject ... his very core, the gesture that opens up the space for the Light of Logos, is absolute negativity, the "night of the world." ... [T] here is no subjectivity without this gesture of withdrawal; that is why Hegel is fully justified in inverting the standard question of how the fall-regression into madness is possible: the real question is, rather, how the subject is able to climb out of madness and reach "normality." That is to say: the withdrawalinto-self, the cutting-off of the links to the environs, is followed by the construction of a symbolic universe which the subject projects on to reality as a kind of substitute-formation, destined to recompense us for the loss of the immediate, pre-symbolic Real. However, as Freud himself asserted ... is not the manufacturing of a substitute-formation, which recompenses the subject for the 
loss of reality, the most succinct definition of . . . the subject's attempt to cure himself of the disintegration of his universe? ${ }^{\text {2 }}$

All the basic elements of Dewey's early philosophy are here. The self negates what is given, moves on from it into its own activities and powers, and creates a substitute world for itself in which it can find the meaning that is absent from the missing facts themselves. In creating these virtual worlds, the self becomes "normal," that is, cultured, as opposed to a mere animal immersed in immediate experiences that have a far less developed meaning-no complex emotions, no morality, no religion. At stake here is precisely the emergence of culture, as Žižek well realizes: "the key point is thus that the passage from 'nature' to 'culture' is not direct, that one cannot account for it within a continuous evolutionary narrative: something has to intervene between the two, a kind of 'vanishing mediator,' which is neither Nature nor Culture." ${ }^{63}$ And the creation of culture, of these ideal virtual worlds, and our absorption in them is a way for a person to be healthy or normal, to "cure" himself, as Žižek says, of "the disintegration of his universe," that is, of "the loss of the immediate ... Real" - or as the early Dewey might suggest, of the absence of the given. ${ }^{64}$ Surprisingly, therefore, the early Dewey and Slavoj Žižek have much in common, having both drawn significantly from Hegel..$^{65}$

Now the important thing about rupture as an explanation of culture, as Žižek's analysis reveals, is that this explanation shows how cultural products can be free and novel products of human activity. Rupture as a process takes us beyond nature and allows, for the first time, distinctly human productions, such as works of art, music, science, and so on. "Something has to intervene" ${ }^{66}$ and break up the natural desire and send it into new and more meaningful directions; there must be rupture, break, discontinuity, a negation of the desire as it is and its push into new avenues. A philosophy of rupture can account for how unique cultural productions occur, namely, as "negated" desires that are stopped, repressed, brought into the mind and intensified in light of its own idiosyncratic tendencies, and then 
transformed into totally new, external, symbolic substitutes for our desires. The natural desire, unable to find expression anywhere, implodes and mutates into a new kind of force, a symbolic substitute for that destroyed part of us, which gets to live on in a new form. This is how we might explain culture-formation for a philosophy of rupture. But can a philosophy of continuity account for novel cultural productions?

Relying on the idea of continuity, the later Dewey has to account for culture in a seamless way, as something that emerges continuously from out of our natural interactions. There can be no sudden eruption of new cultural products into existence. Somehow a symbolic substitute for a natural impulse must arise from the continuous flow of experience. A cultural product has to emerge as does "the growth and development of any living organism from seed to maturity," that is, continuously (LW 12: 30). How does this occur?

The later Dewey says that culture in any given individual emerges when his or her raw impulses are shaped into a coherent set of habits through the customs of society. The individual finds it easy to adopt his society's way of doing things; it is something he does as a matter of course. Dewey puts the point this way in Human Nature and Conduct: "Few persons have either the energy or the wealth to build private roads to travel upon. They find it convenient, 'natural,' to use roads that are already there; while unless their private roads connect at some point with the high-way they cannot build them even if they would" (MW 14: 43-44). Social habits are transmitted through the individual's natural and easy adjustment to custom; the adjustment takes place when the individual's own native impulses are reorganized along the pathways of the society, which occurs in a convenient and natural way for most people.

Dewey elaborates on this point and stresses that we do not actually have much choice in the matter. "If we would live," he says, we must "take some account" of social customs. "Social pressure," he explains, "is but a name for the interactions which are always going on and in which we participate, living so far as we partake and dying so far as we do not" (MW 14: 224). This account of social adjustment 
basically means that one either adjusts to the social customs or one does not; one either adopts the available cultural meanings or one does not. If a person adjusts, he or she gets to live and becomes a functioning member of the society; if a person does not adjust, then he or she dies, is rejected from the group, violence befalls him or her, and so on. We simply do adopt our social norms, "our culture," and that is how culture emerges for us. It is one with our environment, with who we are (insofar as we live), and we quite naturally adopt its ways.

But can this process really give rise to cultural meanings in the individual? People clearly have impulses, at times, that go against their culture, and it may not always be convenient and natural for people to squelch these impulses and redirect them into socially acceptable channels. These impulses, as repressed, would then persist; they would get redirected and find other, new outlets (sometimes creative outlets) in our behavior. There is something too simple and easy in the later Dewey's account of adjustment to society as an either-or, life or death, occurrence. This account seems to preclude repression and its psychic affects-the hidden rifts at work in one's mental life.

The later Dewey does stress, however, that there is something like repression or "suppression" going on, despite the passages quoted above where he suggests otherwise (MW 14: 108ff.). He clearly sees the need for this concept to help explain our behavior, for he offers it as one of three options "in the career of any impulse activity" (MW 14: 108). Along with the direct expression of the impulse without thought, there is the sublimation of the impulse, and there is its suppression (MW 14: 108). Suppression, he says, is problematic because the impulse "is neither exploded nor converted, it is turned inwards, to lead a surreptitious, subterranean life," and this will result in "all kinds of intellectual and moral pathology" (MW 14: 109). The proper result to hope for is sublimation, where the impulse will "become a factor coordinated intelligently with others in a continuing course of action" (MW 14: 108).

But the question is, how are suppression and sublimation possible in a philosophy of continuity? If we first consider suppression, in 
which an impulse is "driven into a concealed, hidden activity" (MW 14: 114), we will want to know whether it is realistic to say that every impulse finds an outlet somewhere, even if in "hidden activity." Are there not some impulses that can never get expressed, that is, whose objects can never be attained? The later Dewey's examples of suppression are relatively benign. For instance, he says that "the imperative demand for companionship not satisfied in ordinary activity is met by convivial indulgence" (MW 14: 109). Examples like this make it easy to see how suppression can occur in a naturalistic philosophy, guided by "the idea of continuity" (LW 12: 30). But notice that Dewey is maintaining here that in suppression, impulses "demand and secure a special manifestation" (MW 14: 109). They always "secure" an outlet in some activity. They always find some comparable object that will satisfy them. An impulse for companionship, for example, will always achieve a social connection somehow, even if in a perverse or dangerous form. But is that correct? Do impulses always "secure" their expression? Do they always attain their objects one way or another? If we imagine less benign examples, in which the object aimed for is never permitted, as Freud, for example, might discuss, then we should probably say instead that not all impulses secure a "manifestation." What then happens to these impulses? Where do they go? What do they become?

The later Dewey wants to say, to be sure, that such impulses can be sublimated, becoming "coordinated intelligently with others in a continuing course of action" (MW 14: 108). Consider the case of art, for example. For the later Dewey, art is definitely the result of sublimation. As he says, "without inhibition there is no instigation of imagination" (MW 14: 114). He believes that "any imagination is a sign that impulse is impeded and is groping for utterance. Sometimes the outcome is ... an articulation in creative art" (MW 14: 113). And his example is that "an excitation of sexual attraction may reappear in art" (MW 14: 108). Some impulse arises, it is thwarted, and it gets intelligently redirected along with other impulses into an accepted channel of activity. Imagination is the creative searching for a new and more acceptable place for the thwarted impulse. A new artwork 
would then arise when intelligence helps the imagination to find a proper outlet for the impulse.

But how exactly doe this process occur? For example, how does "an excitation of sexual attraction ... reappear in art"? The only way it could, given the idea of continuity, is for it to get redirected (it could never get extinguished and be created as something new), ${ }^{67}$ as when social forces, for example, push the impulse into already given, accepted patterns of activity, namely art; or when intelligence and imagination work together to coordinate the impulse with other, preexisting activities similar to art.

Once again, all is smooth and easy in the later Dewey's account of the psyche. Everything stays on the surface, and the re-coordination of a renegade impulse is achieved by its assimilation with accepted cultural forms. The later Dewey, relying on continuity, would say that every impulse gets expressed somewhere, even when it is suppressed or sublimated. For an impulse to be suppressed or sublimated means, for him, that the impulse finds some other area of culture in which to be expressed. There is, in a sense, no real suppression, only redirection. So any "new" production is really only the result of an impulse that finds expression in some existing course of action, modifying that course to some extent, but also getting assimilated by it in a natural and easy way. Something new can therefore emerge, but it will be new in a restricted sense. It is only ever possible to express the impulse in already prescribed channels of activity, to create a meaning in an already prescribed cultural form. As a result, nothing totally sudden and unforeseen is possible.

But then the question arises as to how culture could have arisen from nature in the first place through this mechanism. If continuity is the overriding consideration, and the old merely gets reshuffled in new ways, how can we account for the existence of something like a symbolic substitute for our desires-for new cultural formations in which we find ourselves involved, but which are not simply the expression of some previous desire, but are instead that desire transformed into a new meaning for us? The later Dewey wants to be able to say that such 
a thing is possible, for he will not reduce the cultural product to the natural impulse. But how can he make good this account of things? In our previous example of art, how did the art that could serve as a substitute for sexual attraction arise in the first place? Or more generally, how did the cultural part of that to which I easily assimilate when I assimilate to culture arise in the first place? Every impulse must be either simply acted on or taken up into the existing cultural meanings, but how does any cultural meaning, which would assimilate the impulse, occur at all through this procedure? How does it occur, specifically, when the sublimated impulse itself is not supposed to generate any wholly new cultural meanings, but only, at best, redirect the old ones? How could a natural impulse originally create culture, when culture is required to redirect and assimilate the natural impulse?

As if to solve this problem, the later Dewey is compelled, at one point, to say that we have an impulse for creativity. "In short, among the native activities of the young are some that work towards accommodation, assimilation, reproduction, and others that work toward exploration, discovery and creation" (MW 14: 70). So the native impulse for creation would have to be the one that compels culture to arise. When the creative impulse is allowed to express itself it will lead to cultural meanings, it seems. But how does an impulse know, so to speak, that it is creative? What makes impulses, which are themselves "blind, unintelligent," creative in their nature? (MW 14: 108) ${ }^{68}$ In the view of the later Dewey, an impulse receives meaning and direction from already available cultural meanings. But what defines a creative impulse as creative before there is a culture relative to which the impulse is creative? Sticking with the idea of continuity, which restricts the imagination to finding an appropriate cultural outlet for an impulse, would seem to make it impossible for the imagination to create at any point the cultural meanings in relation to which it would then be a serviceable tool. Cultural meanings, in turn, would seem to be products totally devoid of imagination, nothing truly creative; and creativity would be restricted to those acts in which a renegade impulse was intelligently assimilated into the culture. 
Here there is a fundamental difference between the earlier and the later Dewey. ${ }^{69}$ They would explain the emergence of culture differently, and the earlier Dewey would do so potentially better, with fewer problems, than the later Dewey. Rejecting the idea of continuity, and relying on the logic of rupture, the earlier Dewey might say, as does Žižek a century later, that cultural meaning is always the creation of something totally new, totally other than nature, which occurs through the repression and transformation of our natural desires, through the negation of the given. "Absolute negativity" is involved, in the sense that the natural impulse must die an unnatural death; it must cease to be itself as a natural impulse. The natural impulse must be totally denied, and this denial must lead to a positive new meaning; nature must become antinature, which Žižek explains by saying that "this . . of course, is the death drive." break in continuity, something that is "no longer nature" but "not yet logos," something like the death drive, or the negation of the given, the logic of rupture, can account for the passage to culture. ${ }^{71}$ For nature would only continue its drive; it would not turn against itself and destroy itself. Nature cannot of its own accord develop into antinature and become something new. Through negation and rupture, on the other hand, or the desire of the self to destroy a part of itself, something new is possible. A new meaning can appear when we fight against our impulse, lose a part of ourselves, and encounter a "fall-regression into madness," but then recompense ourselves "by the construction of a symbolic universe," which "the subject projects on to reality as a kind of substitute-formation." 72 There is a void and I seek to fill it. The creative process can occur because cultural products are the result of my own destruction of my nature, brought on by the impermissibility of my impulse. Since the impulse is impermissible, I turn against the impulse and myself in a kind of madness of self-destruction; but the destruction is made good through the creation of culture, the creation of a "symbolic universe" in which I can pursue new impulses and a new version of myself in a different and higher form, or in a better-adjusted state. ${ }^{73}$ There is a return to " "normality" ' in the new figure of the better-adjusted self. ${ }^{74}$ Moreover, in 
this view, the creative process is endless, always promising something new, because an impulse that never attains its object can never be satisfied; it will continue to yearn for its object and keep searching for it, ${ }^{75}$ turning from one object to the next, repeatedly creating symbolic substitutes in the process.

As a naturalist relying on the idea of continuity, the later Dewey seems to be at a loss in explaining the origins of culture. There would seem to be nothing in his account to explain those cases in which, to pass from nature to culture, individual desire to social norm, we have to negate a desire and create a symbolic substitute-when we have to create culture. For him, culture is already assumed, and it works on individual desire. He believes there are acts of assimilation, brought to bear on us as a matter of course by the actions of those in the group to which we belong, and we either adjust to these actions or not (and normally, he thinks, we easily adjust). But such a view does not seem able to account for the emergence of culture in the first place. Moreover, it could be construed as somewhat naïve. Very often we have to force ourselves to adjust and give up all hope of fulfilling our desire. We have to negate our own desires in order to adopt the culture's norms. There must be a sudden break from our natural inclinations. It is not always easy to belong to a group. There must be moments of rupture, in which we compel ourselves to belong, but with this consolation: that we can transform the thwarted desire into a symbolic substitute in which a totally new meaning - in which culture-occurs, and we can find and fulfill our new, unique selves, with new desires, there. Participating in culture is a loss for us; some part of us must die; we must enter the " "night of the world.' "76 That is, some natural desires are not manifested in other activities, but must be obliterated; but we are compensated for this loss by some new cultural meaning, "the Light of Logos," 77 and a new persona in relation to it, in which our new selves can partly find themselves, even if they never fully satisfy themselves in the end.

But if this account of human adjustment is correct, then it is the earlier and not the later Dewey who is better able to account for it. For the later Dewey's philosophy does not have available the concept 
of rupture that is required to explain how we could divide ourselves from ourselves in this way and create new meanings. The philosophy of the earlier Dewey, on the other hand, lends itself readily to the idea that we break from our given desires. His work implies that we are not continuous with ourselves, but are time and again detached and disrupted from ourselves. We become more social in the process, yes, but only by resisting what we have been and pressing forward to new determinations of ourselves, even at the cost of the total submission and denial of these former selves. And the early Dewey recommends that we engage in such breaking away, above all, from the various types of modernist selves that we might have adopted, not to mention from our given and natural egoistic selves.

The later Dewey, by contrast, is hard put to explain how something truly new can occur, specifically culture, which he implies must exist first to assimilate our natural impulses, but which, presumably, as a new and creative product appearing in the world, must have been the result, somehow, of our creative impulses. The problem exists for any naturalist relying on continuity: namely, explaining how the imagination can create anything that is truly new. If the imagination is always continuous with past creations, and its results destined for intelligent assimilation, how can it be imaginative and create something that is $n e w$ ? Mark Johnson notes that accounting for the imagination "may be one of the most difficult problems in all of philosophy." 78 There are no easy answers. But while the early Dewey shows at length in the Psychology how the creative power of rupture produces the actual meanings and values of culture, the later Dewey appears unable to show how the imagination can ever produce anything new, ruled as he is by the idea of continuity and the eternally smooth and easy transference of previous meanings. If we presuppose continuity, it is difficult to see, indeed, "how the new can emerge from the old, yet without merely replicating what has gone before." 79

This whole issue remains an open question, for we certainly cannot decide in these few sentences whether continuity or rupture better explains the shift from nature to culture. This is surely a matter for continued dispute and debate. But the discussion so far should at 
least be enough to give us pause. Perhaps the early Dewey is not correct in maintaining that rupture is the fundamental process of meaning-making. But in stressing that rupture is involved in the transition from nature to culture, he clearly can be said to have advanced insights worthy of consideration, even to the point of posing a challenge to the later Dewey, despite the later Dewey's many great innovations in philosophy.

I conclude, therefore, that Dewey's early philosophy is more significant than many people have realized. The early philosophy marks out new territory in the idealist terrain, as I have shown by demonstrating how it departs from the idealism of Dewey's teacher, Morris, and from traditional readings of Hegel. It anticipates vital movements of contemporary thought in very surprising ways, putting it in league with fascinating new Hegelian thinkers such as Adorno, Derrida, and Žižek. The early philosophy also challenges a prominent form of naturalism today, namely Dewey's own later philosophy. And perhaps most importantly of all, Dewey's early philosophy gives us a way to respond to philosophical pessimism in our own day, and to critique our modern pessimistic culture. It offers us a way to have faith in life. The way pointed by the early Dewey may or may not prove correct in the end, but it certainly merits our consideration insofar as we are concerned at all with fundamental issues-issues of how to live, where to find meaning, and what kind of society we should struggle to create. 
